\title{
OIL AGGREGATED BEHAVIOR FOR COAL RECOVERY AND COMBUSTION CHARACTERISTICS OF THEIR AGGREGATES FROM DIFFERENT GRADE COALS
}

\author{
Q. WANG ${ }^{1}$, H. NIIDA ${ }^{1}$, C. LIU ${ }^{1}$, H. KUROKAWA ${ }^{1}$, A. SARKAR ${ }^{1}$, K. SEKIGUCHI $^{1}$ \& K. SUGIYAMA ${ }^{2}$ \\ ${ }^{1}$ Department of Environmental Science and Technology, Graduate \\ School of Science and Engineering, Saitama University, Japan. \\ ${ }^{2}$ Hachinohe National College of Technology, Japan.
}

\begin{abstract}
Large amounts of waste fine coals are very difficult to be treated due to the presence of ash and inorganic sulphur compounds. In order to use waste fine coal efficiently, a retrieval technique is necessary for the recovery of combustible contents of coal from fine waste coals. Nowadays, a flotation process has been used for the treatment, but it is impractical for developing countries due to its higher costs. Therefore, oil agglomeration process has been used to deal with these problems. In this study, the factors affecting the coal cleaning efficiency of the oil agglomeration process were investigated with the element contents and chemical structure of three different grade coals. Chemical contents in three different grade coals were determined by proximate and ultimate analyses and the differences in chemical structure of carbonaceous contents of different grade coals were investigated by a Fourier transform-infrared spectrometry. In free coals or their mixed samples, the ratio of ash and carbonaceous contents were maintained to make it homogeneous. From the results of oil agglomeration experiments, it was concluded that the characteristics of agglomerate and the coal cleaning efficiency of oil agglomeration were not only influenced by the type of oils but also by the oxygen contents and the aromatic and aliphatic chemical structures in different grade coals. The oxygenic functional groups of carbonaceous contents in coal samples prevented oil from attaching the carbonaceous surface and form the bulky aggregate. This depressed the combustible matter recovery, but this was resolved by changing the oil types. Oxygen contents in oils such as vegetable oil played a role in bridging material to the oxygenic functional groups of carbonaceous contents in coal samples. Meanwhile, it was observed that aromatic functional groups in carbonaceous contents interacted badly with the aliphatic functional groups in oil due to the resonance inspection of delocalized $\pi$ electrons. Comparatively carbonaceous contents consisting of more aliphatic series or graphite-reinforced structures were tended to form aggregates easily. Even when different types of coals were used in the oil agglomeration, it was possible to achieve a better efficiency by taking these factors into account. Moreover, by thermogravimetric-derivative thermogravimetric (TG-DTG) analyses, it was found that the combustion characteristics of carbonaceous contents were improved due to oil attachment.

Keywords: Aliphatic and aromatic contents, ash contents, combustion characteristics, Fourier transform-infrared spectrometry (FT-IR), hydrophobicity, oil agglomeration, TG-DTG, waste fine coal.
\end{abstract}

\section{INTRODUCTION}

Coal production increases continuously worldwide due to the increase in mechanizations in coal mining and demand in its related fields of applications. Especially, coal consumption in China is in multiplying trend, but cleaning problems of waste fine coals are considered as a serious issue because of poor coal cleaning efficiencies. The coal that has more ash and inorganic sulphur contents is difficult to be available as resources and causes a spontaneous combustion, which in turn leads to air pollution, land occupation, soil pollution and water contamination [1]. In order to use waste fine coals efficiently, a retrieval technique is necessary for the recovery of combustible contents of coal from waste fine coals. Flotation process has been used to these coals, but cost is a major problem to operate in developing countries. Therefore, oil agglomeration process (Fig. 1) has attracted attention by addressing these problems, which is a coal cleaning method used for 


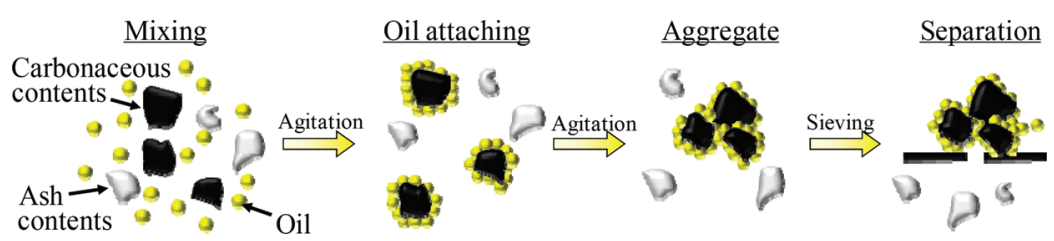

Figure 1: Principle and concept of oil agglomeration for coal cleaning.

determining the differences in surface characteristics between carbonaceous and ash contents [2]. Hydrophobic oil is an aggregating agent that selectively attaches to hydrophobic carbonaceous contents, which form agglomerates. From the previous experiments of different particle sizes, only coal combustible carbonaceous contents from waste coals were recovered successfully and ash contents were removed [3-5].

The optimum conditions for oil agglomeration experiments have been searched in various studies in relation to parameters such as agitating time or speed, type or concentration of aggregating agents and addition of electrolytes to water solvents [5-8]. So, the main objectives were to recover combustible matters and remove ash as well as sulphur contents under optimum conditions that had beneficial effects on coals. There are many types of coals present all over the world, and some of them are difficult to recover by the oil agglomeration process because every coal has its own characteristics that are different from each other. In general, coals are classified as anthracite coal, bituminous coal, brown coal and peat. The low-grade coal has less carbon content, low calorific value and more oxygen content and is hydrophilic [8]. Eventually, with the increase of oxygenic functional groups in carbonaceous contents, they become more hydrophilic, preventing oil, which is hydrophobic, from attaching the carbonaceous surfaces, which depresses coal cleaning efficiencies. For actual utilization of oil agglomeration process, developments in compatible processes depends on the type of coals, because it may be impossible to recover waste coals from same surface and chemical structures of carbonaceous contents. In this study, the factors affecting coal cleaning efficiencies of the oil agglomeration process were investigated with three different grade coals varied in element contents and chemical structures of carbonaceous contents. In addition, the combustion characteristics of aggregates were determined by thermogravimetric-derivative thermogravimetric (TG-DTG) analyses. In this study, more detailed experiments were carried out and added different results with a conference paper published in the 4th International Conference on Energy and Sustainability [9].

\section{MATERIALS AND METHODS}

\subsection{Sample preparations}

Samples of the different grade coals such as Chongqing coal, Furong coal of China and Adaro coal of Indonesia were selected as different grades of anthracite coal, bituminous coal and lignite coal, respectively. Different coal samples were mixed and the particle sizes of these samples were screened by adjusting 53-75 $\mu \mathrm{m}$ of several sieves. The proximate and ultimate analyses of coal samples were carried out according to the Japanese Industrial Standard (JIS) method of JIS-M8812.

The results of proximate analysis and ultimate analyses of coal samples are shown in Table 1. It was revealed that the ratios of ash contents were different in different coals. The ratio values of 
Table 1: Results of proximate and ultimate analyses of three different grade coal samples.

\begin{tabular}{|c|c|c|c|c|c|c|c|c|c|}
\hline \multirow[b]{2}{*}{ Coal sample } & \multicolumn{4}{|c|}{ Proximate analysis (wt $\%$ ) } & \multicolumn{5}{|c|}{ Ultimate analysis (wt\%) } \\
\hline & Ash & $\mathrm{M}$ & $\mathrm{VM}$ & $\mathrm{FC}$ & $\mathrm{C}$ & $\mathrm{H}$ & $\mathrm{N}$ & $\mathrm{O}$ & S \\
\hline Chongqing & 11.9 & 2.4 & 18.9 & 66.8 & 90.7 & 4.7 & 1.6 & 3.0 & 0.045 \\
\hline Furong & 24.8 & 3.1 & 15.2 & 56.9 & 80.0 & 4.0 & 1.5 & 10.5 & 4.0 \\
\hline Adaro & 3.3 & 9.3 & 45.7 & 41.7 & 62.4 & 5.3 & 1.1 & 31.5 & 0.11 \\
\hline
\end{tabular}

M: moisture, VM: volatile matter, FC: fixed carbon.

oxygen contents were Adaro coal > Furong coal > Chongqing coal, which were determined by the proximate analysis. The volatile matter of Chongqing coal consisted of $90 \%$ carbon contents and $3 \%$ oxygen contents, which indicated the necessity of more detailed investigation on the coal sample structure.

\subsection{Acid digestion treatments of raw coal samples}

In order to prepare ash-free coal samples, the coal samples were needed to undergo acid digestion treatment. For oil agglomeration process, the ratios of carbonaceous contents and ash contents were adjusted. $\mathrm{HCl}$ and $\mathrm{HF}$ acid solutions were used in the method of acid digestion treatment, which reduced the ash contents to prepare ash-free coal samples [10]. Therefore, Adaro coal was not treated in this way because of its low ash content. The $\mathrm{HCl} / \mathrm{HF}$ acid digestion treatment procedure is presented in Table 2.

The indicated masses of coals were treated in the aqueous $\mathrm{HCl}$ solutions for 24 hours as Part 1 of the digestion treatment. The remaining coals were filtered and washed with tap water and ultrapure water to remove $\mathrm{HCl}$ until the $\mathrm{pH}$ was 7.0. After that the samples were digested with $\mathrm{HF}$ as Part 2 of the digestion treatment similar to Part 1, but in the Teflon beaker. After filtering and washing, the $\mathrm{HCl}$ acid digestion treatment procedure of Part 3 was conducted. The acid-treated coals were similarly washed to remove the remaining acid and then determined by the proximate analysis. The ash contents decreased about 3.0\% after acid digestion treatment. Chongqing coal and Furong coal and original Adaro raw coal (ash-free coals) were used in the analysis of chemical structure and oil agglomeration experiments after the acid digestion treatment.

\subsection{Analyses of chemical structures of carbonaceous contents by Fourier-transform infrared spectrometry}

In order to investigate qualitatively, the chemical structures of carbonaceous contents in different grade coal samples were analysed based on the Fourier-transform infrared spectrometry (FT-IR). The infrared spectra were recorded using a Model IR-6100 (Jasco Corporation, Japan) interfaced with a personal computer operating with Windows-based spectra manager (Version 2). First, ash-free coal samples were sufficiently ground and mixed with $\mathrm{KBr}$ at the proportion of 1:200 (coal: $\mathrm{KBr}$ ). Mixtures were moulded into a $5 \mathrm{~mm} \phi$ pellet, and the sample tablets were made. All pellets were dried at $107^{\circ} \mathrm{C}$ for $15 \mathrm{~min}$ in order to prevent moisture effect from air. The spectra were recorded from 4,000 to $400 \mathrm{~cm}^{-1}$, and the scan numbers were 256 at the resolution of $4 \mathrm{~cm}^{-1}$. But carbona- 
Table 2: Experimental conditions for acid digestion treatments to be ash free.

\begin{tabular}{|c|c|c|c|c|c|c|c|c|}
\hline \multirow[b]{2}{*}{ Coal sample } & \multirow[b]{2}{*}{$\begin{array}{c}\text { Coal } \\
\text { mass }(\mathrm{g})\end{array}$} & \multicolumn{2}{|c|}{ Part 1} & \multicolumn{2}{|c|}{ Part 2} & \multicolumn{3}{|c|}{ Part 3} \\
\hline & & $\mathrm{HCl}(\mathrm{M})$ & $\begin{array}{c}\mathrm{HCl} \\
\text { vol. }(\mathrm{mL})\end{array}$ & $\mathrm{HF}(\%)$ & $\begin{array}{c}\text { HF } \\
\text { Mass (g) }\end{array}$ & $\mathrm{HCl}(\mathrm{M})$ & $\begin{array}{c}\mathrm{HCl} \\
\text { vol. }(\mathrm{mL})\end{array}$ & $\operatorname{Ash}(\%)$ \\
\hline Chongqing & 100 & 5.00 & 208 & 40.0 & 208 & 5.00 & 208 & 0.802 \\
\hline Furong & 100 & 5.00 & 433 & 40.0 & 433 & 5.00 & 433 & 3.01 \\
\hline
\end{tabular}

Table 3: Absorption bands of functional groups of carbonaceous contents in coals usually observed in FT-IR spectra.

\begin{tabular}{ll}
$\begin{array}{l}\text { Absorption bands of function } \\
\text { groups }\left(\mathrm{cm}^{-1}\right)\end{array}$ & \multicolumn{1}{c}{ Assignment (functional groups and their vibrations) } \\
\hline 3,390 & Stretching vibrations O-H group and $-\mathrm{OH}$ groups \\
3,046 & Aromatic C-H groups \\
2,921 & Asymmetric C-H stretching vibrations of aliphatic groups \\
2,853 & Symmetric C-H stretching vibrations of a aliphatic groups \\
1,698 & COOH groups \\
1,603 & Highly conjugated $\mathrm{C}=\mathrm{O}$ groups \\
$875-750$ & Aromatic C-H groups \\
\hline
\end{tabular}

ceous contents in coals have many functional groups [11]. That is why some recorded spectra went over with respect to one another. For the precise evaluation of the chemical structure of each coal, we focused on functional groups that contained oxygen contents, aliphatic $\mathrm{CH}$ and aromatic $\mathrm{CH}$ in order to resolve the problem. Table 3 explains the principal functional groups observed in the spectra. For a background measurement, about $1 \mathrm{mg}$ of ground $\mathrm{KBr}$ was moulded into a $5 \mathrm{~mm} \phi$ pellet to form $\mathrm{KBr}$ tablet and the measurement was conducted in same way.

\subsection{Oil agglomeration experiments}

A schematic diagram of oil agglomeration procedure is shown in Fig. 2, and the experimental conditions are given in Table 4. Initially, tap water and the ash-free coal were added to a $500 \mathrm{~mL}$ beaker and mixed. After the mixture being suspended, kerosene or vegetable oil was poured into the beaker as an aggregating agent, and the aggregate was formed. When the aggregate was steady, the agglomerates in the water were filtered with $75,150,250$ and $500 \mu \mathrm{m}$ sieves in order to investigate the growth of agglomerations, which were classified every agglomerates according to the particle size. The agglomerates were filtered and dried overnight at the room temperature and washed with ethanol and diethyl ether to remove oil in the aggregates and kept for drying overnight at the room temperature again $[5,6]$. In fact, for an industrial application, solvent washing steps of agglomerates would not be necessary and coal/oil agglomerates could be used directly as fuel because of the low pollutants in the oil. For evaluation of experiments, the weight of every particle and residual oil attached to the carbonaceous contents was measured and calculated by eqns (1) and (2). Equation (1) 
Table 4: Experimental conditions of oil agglomeration with ash-free coals.

\begin{tabular}{ll}
\hline Item & \multicolumn{1}{c}{ Experimental conditions } \\
\hline Sample & Ash-free coal: $5.00 \mathrm{~g}$ \\
Water & $200 \mathrm{~mL}$ \\
Oil & $1.00 \mathrm{~g}$ \\
Agitation 1 & Time: 3 min, Speed: $1,000 \mathrm{rpm}$ \\
Agitation 2 & Time: 3 min, Speed: $1,000 \mathrm{rpm}$ \\
Standing time & 3 min \\
\hline
\end{tabular}

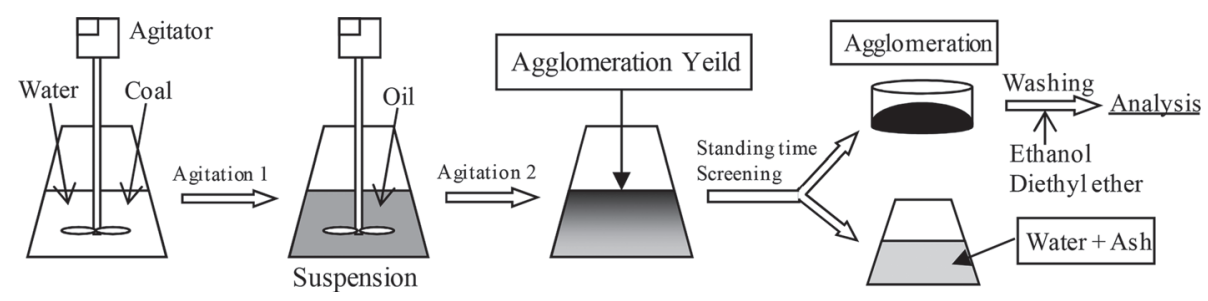

Figure 2: Schematic diagram for steps of oil agglomeration experiment.

is the ratio of particle sizes of agglomerations, which indicates the growth of the agglomerates. Equation (2) is the ratio of oil adhesion, which means the mass percentage of oils used in the agglomeration process. It may be a factor for oil to attach on the surfaces of carbonaceous contents. The oil adhesion was calculated by the weight difference when oil in agglomeration was washed with organic solvent. Moreover, only vegetable oil was used because kerosene will be volatilized while drying.

$$
\begin{aligned}
& \text { Ratio of agglomeration size }(\%)=w t_{\mathrm{X} \mu \mathrm{m} \text { agglom }}(\mathrm{g}) / w t_{\text {agglom }}(\mathrm{g}) \times 100 \\
& \text { Oil adhesion }(\%)=\left(w t_{1}(\mathrm{~g})-w t_{2}(\mathrm{~g})\right) / w t_{\text {accretive oil }}(\mathrm{g}) \times 100
\end{aligned}
$$

In eqn (1), agglom means recovered aggregates, $w t$ means weight unit $(\mathrm{g})$. X indicates ratios of different agglomeration sizes: 75-150, 150-250, 500-250 and $>500 \mu \mathrm{m}$, and $w t_{\mathrm{X} \mu \mathrm{m} \text { agglom }}$ means weight of aggregates recovered by each sieving. In eqn (2), $w t_{1}$ is weight of aggregates before washing oil, $w t_{2}$ is weight of aggregates after washing oil and $w t_{\text {accretive oil }}$ is about $1.00 \mathrm{~g}$ (Table 4).

Actually, waste coals contain large amounts of ash contents, but in the case of the oil agglomeration with ash-free coals, ash contents were not reappeared. Consequently, as a sample, mixture samples of $5.00 \mathrm{~g}$ ash-free coals and $5.00 \mathrm{~g}$ model ash (was from the combustion ash of coal) were used for the oil agglomeration experiment according to the procedures of the experiment discussed in this section. When sieving in water, the resultant agglomerate products were separated from ash contents by below $75 \mu \mathrm{m}$ sieving. For recovered agglomeration, each particle size was gathered and ash contents were determined by the proximate analysis for next evaluations of coal cleaning efficiencies. The efficiencies of a coal cleaning process were calculated by the percentage (wt $\%$ ) of 
the combustible matter recovery $(C M R)$, the ash removal $(A R)$ and the efficiency index $(E I)$ from ash contents in cleaned coal $[3,5]$. These parameters can be calculated by eqns (3)-(5), where CM is 100 - (ash contents) and feed is the weight of coal sample.

$$
\begin{gathered}
C M R(\%)=C M_{\text {agglom }}(\mathrm{wt} \%) \times w t_{\text {agglom }}(\mathrm{g}) /\left(C M_{\text {feed }}(\mathrm{wt} \%) \times w t_{\text {feed }}(\mathrm{g})\right) \times 100 \\
A R(\%)=100-A s h_{\text {agglom }}(\mathrm{wt} \%) \times w t_{\text {agglom }}(\mathrm{g}) /\left(A s h_{\text {feed }}(\mathrm{wt} \%) \times w t_{\text {feed }}(\mathrm{g})\right) \times 100 \\
E I(\%)=C M R(\%)+A R(\%)
\end{gathered}
$$

\subsection{TG-DTG analyses for determining combustion characteristics of aggregates}

For determining the combustion characteristics of three different grade coals and aggregates, TGDTG curves were investigated using a TA-60WS (SHIMADZU). An aggregate sample of $2.00 \mathrm{mg}$ was taken, reactive gases of clean air were kept at $40 \mathrm{~mL} \mathrm{~min}^{-1}$ and a temperature was applied from a room temperature to $1,000 \mathrm{~K}$ at $15.0 \mathrm{~K} \mathrm{~min}^{-1}$ for this experiment. Characteristic parameters could be deduced to determine the combustion property of the tested sample and mainly include $T_{\mathrm{i}}$, the ignition temperature; $\mathrm{DTG}_{\max }$, the maximum mass loss rate during the combustion process; $T_{\max }$, the corresponding temperature of $\mathrm{DTG}_{\max }$ and $\Delta T_{1 / 2}$, the half peak width, which is the temperature difference between two temperatures at the mass loss rate of $\mathrm{DTG}_{\max }$ by a factor of $0.5 . T_{\mathrm{h}}$ is the burnout temperature that is defined as the temperature at which the mass loss rate is less than $1.0 \times 10^{-4} \mathrm{~s}^{-1}$. Furthermore, an integration parameter of $H_{\mathrm{F}}$ is involved and described as follows:

$$
H_{\mathrm{F}}=T_{\max } \times \ln \left(\Delta T_{1 / 2} / \mathrm{DTG}_{\max }\right)
$$

$H_{\mathrm{F}}$ describes the rates and intensities of combustion processes and the smaller value represents the better combustion property. Moreover $\alpha_{\mathrm{T}}$ shows a conversion of combustible parts of the sample at each temperature and it is described as follows:

$$
\alpha_{\mathrm{T}}=\left(w_{0}-w_{\mathrm{T}}\right) /\left(w_{0}-w_{\infty}\right)
$$

For a profound understanding of combustion mechanisms, kinetic parameters; reaction order, $n$; pre-exponential factor, $A$ and activation energy, $E$, could be further calculated from TG-DTG curve and represented as follows:

$$
\begin{gathered}
\ln \left(-\ln \left(1-\alpha_{\mathrm{T}}\right) / T^{2}\right)=\ln (A \mathrm{R} / \beta E)-E / \mathrm{R} T(n=1) \\
\ln \left(\left(1-\left(1-\alpha_{\mathrm{T}}\right)^{1-\mathrm{n}}\right) / T^{2}(1-n)\right)=\ln (A / \beta E)-E / \mathrm{R} T(n \neq 1)
\end{gathered}
$$

$\beta$ is a linear temperature heating rate $(\beta=\mathrm{dT} / \mathrm{dt}=$ constant $)$. This is called Coats-Redfern method [12]. In this analysis aggregate was formed with vegetable oils because kerosene will be volatilized during air drying.

\section{RESULTS AND DISCUSSION}

\subsection{FT-IR spectra of ash-free coal samples}

FT-IR spectra of ash-free coal samples are presented in Fig. 3. An absorption at 3,390 $\mathrm{cm}^{-1}$ was assigned to stretching vibrations of $-\mathrm{OH}$ and $\mathrm{O}-\mathrm{H}$ groups, and an spectrum at $1,603 \mathrm{~cm}^{-1}$ was an absorption highly conjugated with stretching vibration of $\mathrm{C}=\mathrm{O}$ group $[10,11]$. If many oxygenic 


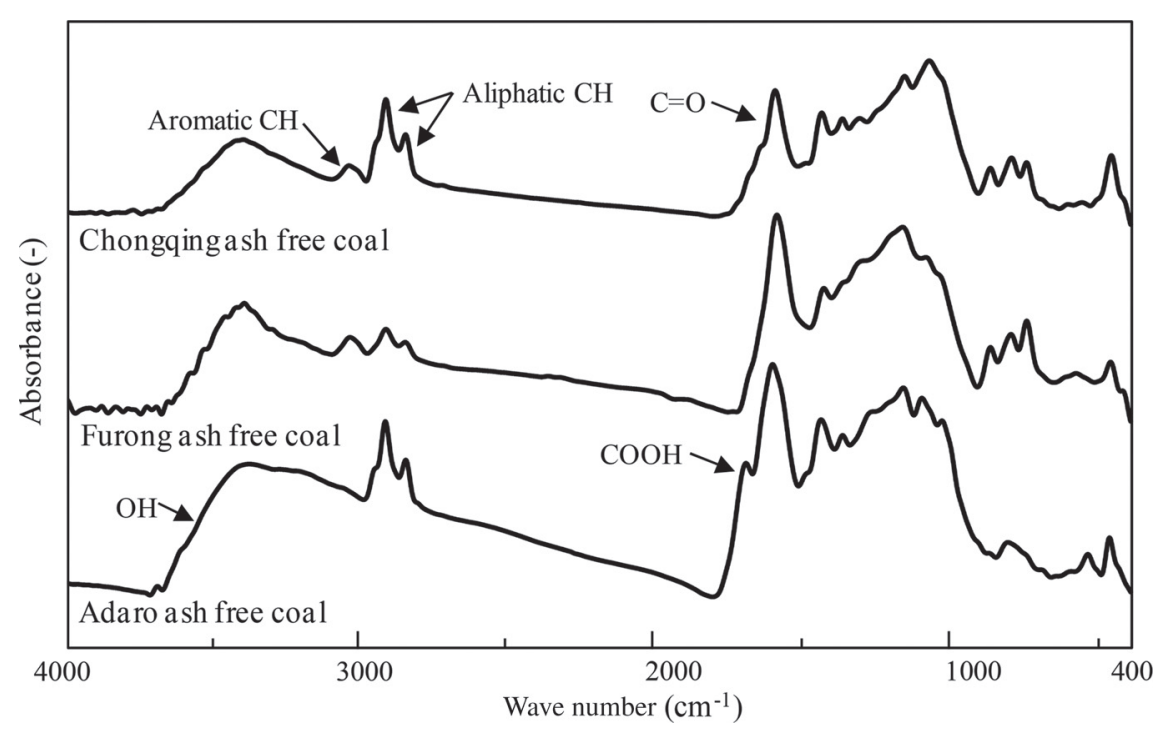

Figure 3: FT-IR spectra of three kinds of ash-free coal samples.

functional groups were present in coal samples, these two peaks pronouncedly became strong. Also, a peak of $\mathrm{COOH}$ group was only observed at $1,700 \mathrm{~cm}^{-1}$ in Adaro ash-free coal because of many oxygenic functional groups and low coalification. Then, the surface feature of Adaro ash-free coal is more hydrophilic than that of other coal samples. $\mathrm{C}=\mathrm{O}$ groups appeared in each coal samples, which were also affected by atmospheric $\mathrm{CO}_{2}$.

Aliphatic groups were observed at $2,921 \mathrm{~cm}^{-1}$ as asymmetric $\mathrm{C}-\mathrm{H}$ stretching vibrations and at $2,853 \mathrm{~cm}^{-1}$ as symmetric $\mathrm{C}-\mathrm{H}$ stretching vibrations. For the low-grade rank, Adaro ash-free coal has many aliphatic functional groups, which indicate that chemical structure of Adaro ash-free coal contain many aliphatic and hydrophilic oxygenic functional groups.

An aromatic $\mathrm{C}-\mathrm{H}$ group at $2,853 \mathrm{~cm}^{-1}$ was assigned from an inflexion point and this peak was usually small and not well defined [11]. However, this peak of Furong ash-free coal was clear and notable. Therefore, Furong ash-free coal may not show the graphite-reinforced structures due to the presence of dotted one or two benzene rings in its carbonaceous structures of the coal. However, Chongqing ash-free coal had more carbon content and less oxygen content, which led to the coalification. Absorption of aromatic $\mathrm{C}-\mathrm{H}$ groups is not shown because many benzene rings were united and aromatic absorption did not occur.

\subsection{Results of oil agglomeration experiments with ash-free coals}

Figure 4 shows the results of oil agglomeration experiments with ash-free coals. These results represent the characteristics of agglomerate. These results were considered and discussed with a focus on oxygenic function groups, aromatic/aliphatic groups and oil structure.

\subsubsection{Inhibition of oil attachment by oxygen contents}

The computational results of oil adhesion show the amounts of oil present in the agglomeration; a trend of Chongqing ash-free coal $(93.1 \%)>$ Furong ash-free coal $(75.6 \%)>$ Adaro ash-free coal 


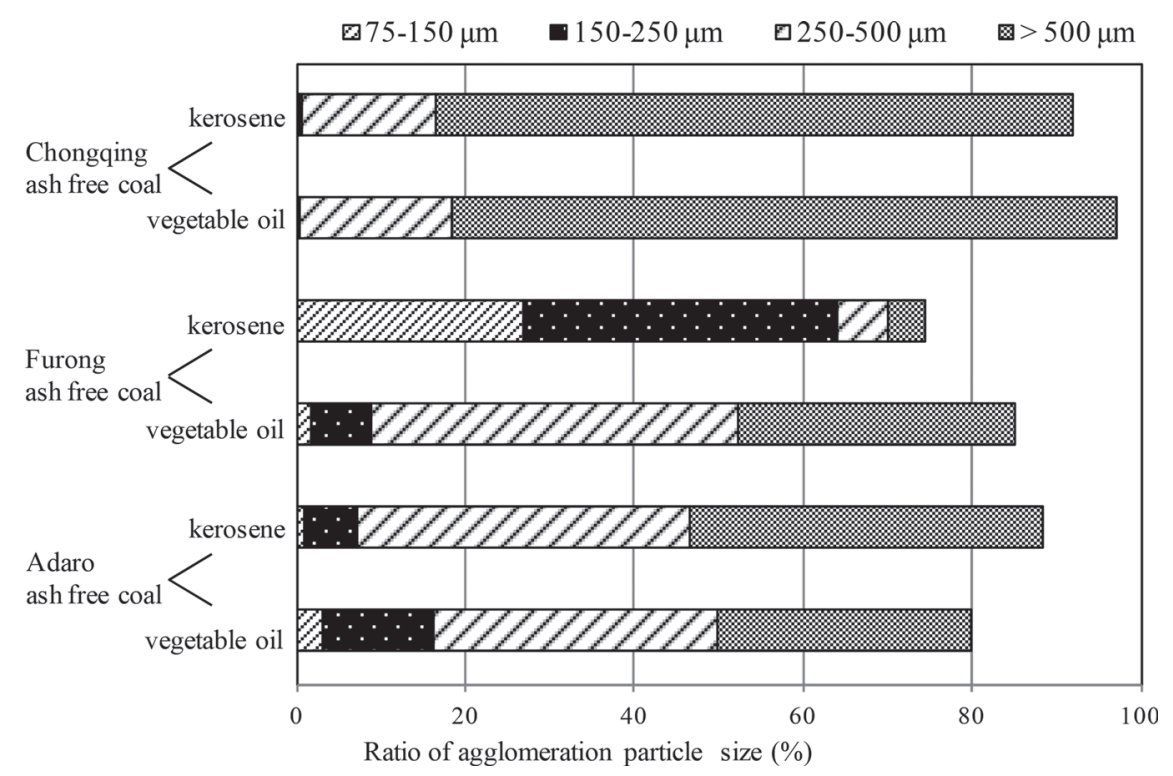

Figure 4: Particle size distributions of aggregates from oil agglomeration experiments with ash-free coals.

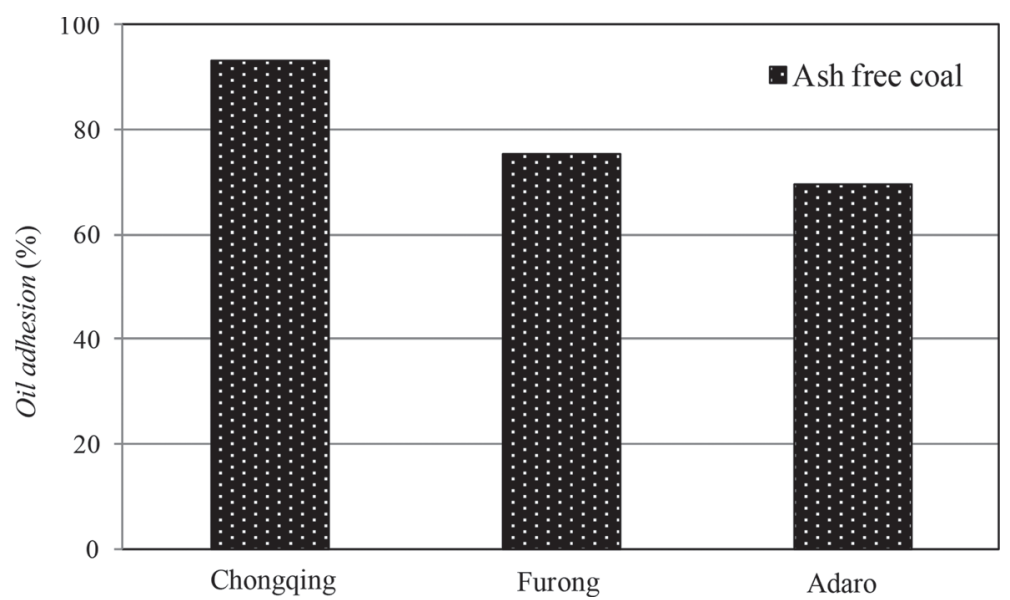

Figure 5: Oil adhesions of aggregate from oil agglomeration experiments with ash-free coals.

(69.8\%) is shown in Fig. 5. When the carbonaceous contents contain more oxygenic functional groups, less oil attaches to the surface of the carbonaceous content. In other words, the hydrophilic functional groups prevent hydrophobic oils from adhering to the surface of the carbonaceous contents [13]. Figure 4 shows that the agglomerates of Chongqing ash-free coal had many oils attached compared with any other coal samples. Moreover, it occupied mostly in the case of the particle size ratio $>500 \mu \mathrm{m}$. On the other hand, Furong and Adaro ash-free coal samples showed less oil attachment and its agglomerates did not grow well in comparison. From these results, it can be thought that 
many hydrophilic functional groups in carbonaceous contents cause inhibition of oil attachment, and carbonaceous contents adhered with many oils form bigger agglomeration and can be recovered easily.

\subsubsection{Effects of aromatic and aliphatic groups}

In general, graphizations of coals generate resonance inspections of delocalized $\pi$ electrons. Aromatic functional groups make the surfaces of carbonaceous structures less bias to charges. Therefore, coal surfaces become electrically stabilized. Meanwhile, it is difficult for aliphatic groups in carbonaceous contents and oils because aliphatic groups cause not only hydrophobic interactions or dipole-dipole interactions but also oil agglomeration due to little dipole moment in the structures.

The Adaro ash-free coal formed slightly slow growing bigger agglomerations compared with Furong ash-free coal due to the presence of large amounts of aliphatic groups. On the other hand, Furong ash-free coal did not go well between coal and oil because it had slight graphite-reinforced structures. In the case of high-grade Chongqing ash-free coal, it was easy to be aggregated because it indicated strong hydrophobic nature and interactions due to the presence of many united benzene rings and aromatic groups.

\subsubsection{Differences between structures of oil types}

Kerosene consists of aliphatic groups and vegetable oil has some oxygen contents. Normally oxygen content decreases coal cleaning efficiencies (Figs 4 and 5), but it was dependant on combinations of coals and oils. It is reported that hydrophilic oxygen contents in vegetable oils such as free fatty acids or aldehyde groups play a role in bridging materials to oxygenic functional groups in carbonaceous contents $[5,6]$. In the oil agglomeration of Furong ash-free coal with kerosene, the particle size of agglomeration was enormously smaller than with other conditions. It occurred because aromatic groups of Furong ash-free coal and aliphatic groups of kerosene interacted badly. However, in the case of experiments with vegetable oil, it improved because the oxygen content of Furong ashfree coal and vegetable oil interacted with each other spontaneously. Generally, bituminous coal like Furing ash-free coal is difficult to recover by oil agglomeration process because of poor balance between aliphatic and aromatic functional groups. However, these coals can be recovered by applying characteristic features of oxygenic functional groups between coals and oils.

\subsection{Results of oil agglomeration experiments simulated waste coals}

The results of particle size distributions of aggregates from oil agglomeration experiments simulating waste coals are shown in Figs 6 and 7. Coal cleaning efficiencies of different grade coals are discussed in this section.

\subsubsection{Factors affecting recovery of combustible matters}

Agglomerated behaviours of three coals are quite similar (Fig. 4). However, the agglomerates of Furong and Adaro mixed sample did not grow so much due to the presence of ash contents in a suspension. Ash contents may avoid interaction between carbonaceous contents and oil and thereby the formation of aggregates. In the cases of Furong and Adaro mixed sample, it was more difficult to aggregate. Therefore, $C M R$ of two coals were low. In addition, ratios of oil adhesion may have a relationship with $C M R$. Comparing experiments with only ash-free coal, oil adhesion of Chongqing mixed sample showed a similar value of $90.2 \%$, but the value for Furong and Adaro mixed sample decreased to $55.4 \%$ from $75.6 \%$ and $35.4 \%$ from $69.8 \%$, respectively, as shown in Fig. 8. The ash contents in suspensions decreased not only the selectivity properties but also CMR. 


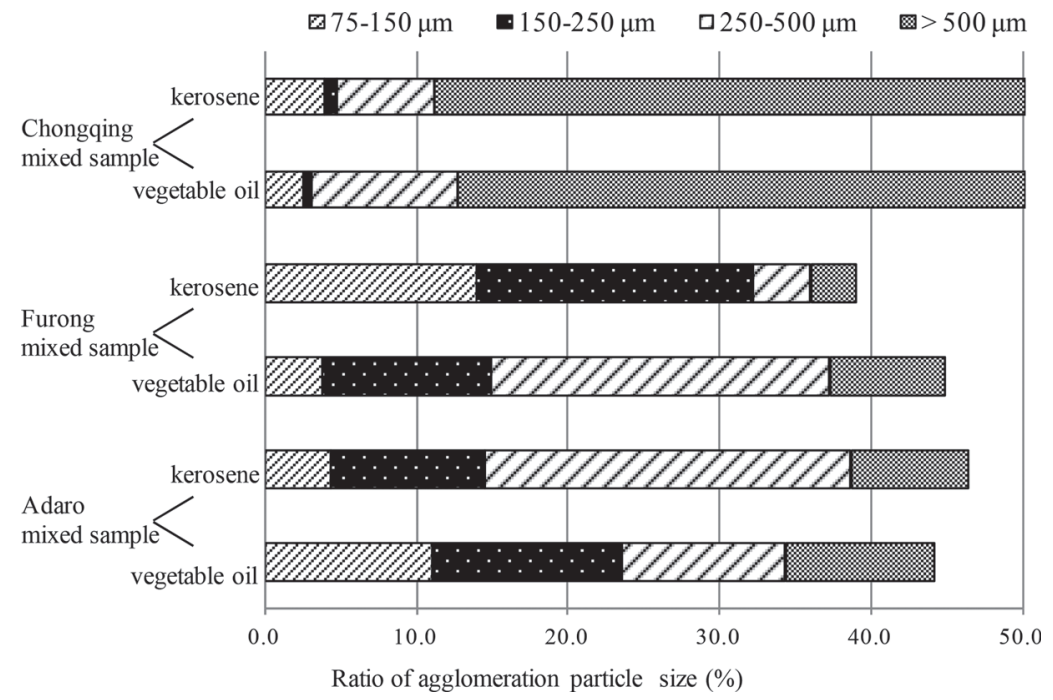

Figure 6: Particle size distribution of aggregate from oil agglomeration experiment with mixed coal sample simulated waste coals.
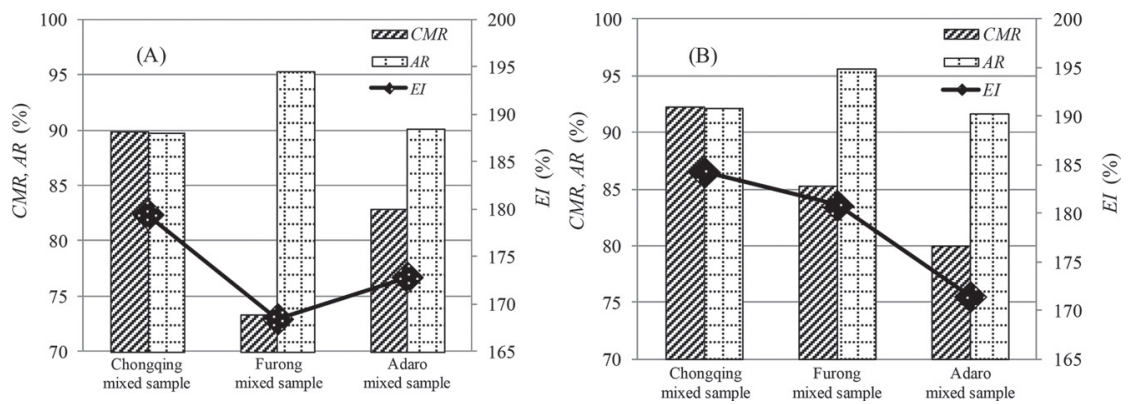

Figure 7: Comparisons of coal cleaning efficiency of oil agglomerations simulated waste coals, (A) with kerosene and (B) with vegetable oil.

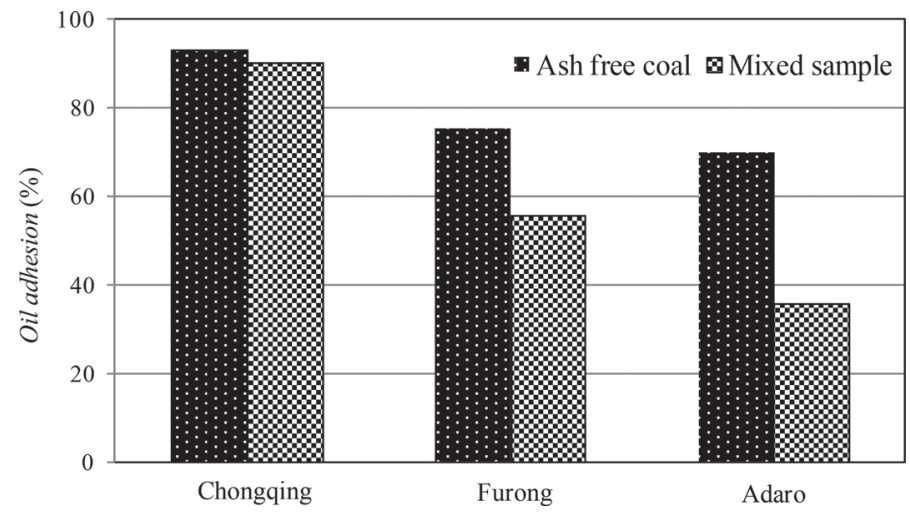

Figure 8: Changes of oil adhesions in the case of ash-free coal and mixed sample that contains ash contents. 


\subsubsection{Reasons for decrease in ash}

Chongqing mixed sample showed higher $C M R$ because it was easy for Chongqing ash-free coal to aggregate. However, there was still a problem that the ash contents might be also took into the aggregate during oil agglomeration processes. Therefore, $A R$ of Chongqing mixed sample were slightly lower than that of other coal samples. $A R$ of Adaro mixed sample was also low, which is thought to be the reason for the interaction between ash and oxygen contents that had hydrophilic properties [12, 14].

\subsubsection{Evaluations of coal cleaning efficiencies}

The results from these two experiments show that coal composed of high carbon content is tended to have good coal cleaning efficiencies because of little negative factor such as oxygen content. Considering oil agglomeration for Furong and Adaro coal, combination of aliphatic or aromatic groups of coals and oil is the important factor for oil agglomeration. In other words, although lowgrade coals have less carbon content, it can be sufficiently recovered to find out optimum conditions.

\subsection{Comparisons of combustion characteristics between three different grade} coals and its aggregates

The results of TG analyses and the characteristic parameters are given in Fig. 9A and Table 5, respectively.

Table 5: Characteristic parameters obtained from TG-DTG analysis and activation energy from Coats-Redfern method.

\begin{tabular}{lccccccc}
\hline Sample & $T_{\mathrm{i}}(\mathrm{K})$ & $T_{\mathrm{h}}(\mathrm{K})$ & $T_{\max }(\mathrm{K})$ & $D T G_{\max }\left(\times 10^{-3} \mathrm{~s}^{-1}\right)$ & $\Delta T_{1 / 2}(\mathrm{~K})$ & $H_{\mathrm{F}}$ & $E\left(\mathrm{~kJ} \mathrm{~mol}^{-1}\right)$ \\
\hline Chongqing & 759 & 860 & 823 & 5.50 & 69.1 & 2.08 & 85.2 \\
Chongqing $_{\text {agglom }}$ & 739 & 851 & 818 & 5.25 & 67.3 & 2.09 & 72.4 \\
Furong $_{\text {Furong }}$ & 773 & 856 & 837 & 5.50 & 67.1 & 2.09 & 108 \\
Adarglom $_{\text {Adaro }}$ & 753 & 853 & 835 & 5.00 & 67.5 & 2.17 & 63.5 \\
Adaro $_{\text {agglom }}$ & 678 & 760 & 721 & 5.75 & 59.1 & 1.68 & 58.1 \\
\hline
\end{tabular}
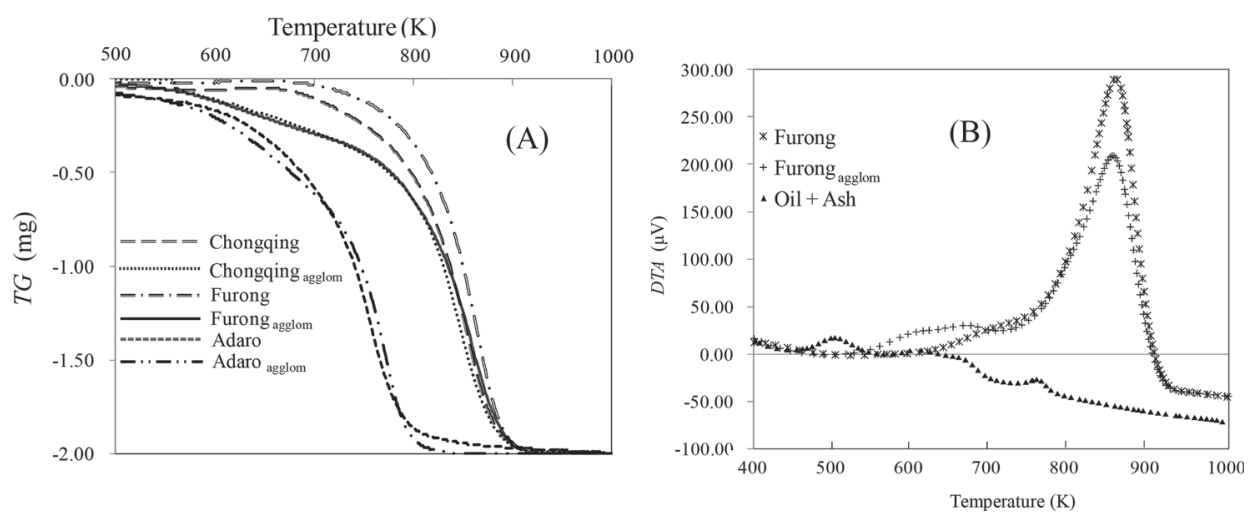

Figure 9: Comparison of combustion characteristics of aggregate obtained from oil agglomeration process. (A) TG analysis curve and (B) DTA analysis curve. 
Combustions and its behaviours of Adaro mixed sample were not improved because of less oil attachments to the surfaces of carbonaceous content. For Chongqing and Furong mixed samples, a decrease in weight was seen at the early stages due to oil attachment and it showed low ignition temperatures. On the other hand, $H_{\mathrm{F}}$ value of Furong mixed sample was weak. Moreover, the decrease in $E$ value indicates that the reactivity of coals was better. From this result, it can be suggested that combustion characteristics of carbonaceous contents of many oil attach are inclinable to be improved. For better understanding of agglomerate combustion, DTA analysis was also conducted, which included three results of vegetable oil, Furong coal and its aggregate (Fig. 9B). In order to find the differences of combustion characteristics between coal and oil, oil sample was soaked through combustion ash contents of coals at the same amounts against all aggregates. The DTA curves showed that three samples have different behaviours and concluded that oil attached to the surfaces of carbonaceous content during oil agglomeration processes promoted better combustions of coals.

\section{CONCLUSIONS}

In this study, the influential factors in the oil agglomeration process for coal recovery were investigated and found that some interesting parameters like the presence of oxygenic functional groups in carbonaceous contents prevent oil from attaching to the carbonaceous surface and forming the bulky aggregate. Hence, $C M R$ and $E I$ were depressed, which could be improved by changing the oil type. Oxygen contents in oil such as vegetable oil played a role in bridging material to the oxygenic functional groups in carbonaceous contents, which improved coal cleaning efficiency of some coals. Aromatic groups in carbonaceous contents had the resonance inspection of delocalized $\pi$ electron and interacted badly with aliphatic groups in oil. Therefore, the carbonaceous contents having more aliphatic groups tend to form the aggregate easily. However, this trend is not applicable to high-grade coal due to developed coalification. Moreover, combustion characteristics of carbonaceous contents were improved due to oil attachment.

\section{ACKNOWLEDGEMENT}

Some works of this study were supported by the special funds for Basic Researches (B) (No. 22404022, FY2010 2012) of Grant-in-Aid for Scientific Research of the Japanese Ministry of Education, Culture, Sports, Science and Technology (MEXT), Japan.

\section{REFERENCES}

[1] World Energy Outlook 2007 - China's Energy Prospects, ISBN: 978-92-64-02730-5, IEA.

[2] Valdes, A.F. \& Garcia, B., On the utilization of waste vegetable oils (WVO) as agglomerants to recover coal from coal fines cleaning waste (CFCW). Fuel, 85, pp. 607-614, 2006.

[3] Alonso, M.I., Valdes, A.F., Martinez-Tarazona, R.M. \& Garcia, B., Coal recovery from coal fines cleaning wastes by agglomeration with vegetable oils: effects of oil type and concentration. Fuel, 78, pp. 753-759, 1999. doi: http://dx.doi.org/10.1016/S0016-2361(98)00218-X

[4] Gurses, A., Doymus, K. \& Bayrakceken, S., Selective oil agglomeration of brown coal: a systematic investigation of the design and process variables in the conditioning step. Fuel, $\mathbf{7 5}$, pp. 1175-1180, 1996. doi: http://dx.doi.org/10.1016/0016-2361(96)00077-4

[5] Wang, Q., Kashiwagi, N., Apaer, P., Chen, Q., Wang, Y. \& Maezono, T., Study on coal recovery technology from waste fine Chinese coals by a vegetable oil agglomeration process. WIT Transactions on Ecology and the Environment, Vol. 142, The Sustainable World, ed. C.A. Brebbia, WIT Press: Southampton, pp. 331-342, 2010, ISSN 1743-3541, doi: 10.2495/SWS100311.

[6] Wang, Q., Kashiwagi, N., Apaer, P., Chen, Q., Wang, Y., Maezono, T. \& Niida, D., Recovery of combustible matter from waste fine Chinese coals by a waste vegetable oil agglomerating 
process and its combustion characteristics. WIT Transactions on Ecology and the Environment, Vol. 143, Energy and Sustainability III, eds. C.A. Brebbia, A.M. Marinov \& C.A. Safta, WIT Press: Southampton, pp. 327-338, 2011, ISSN 1743-3541, doi: 10.2495/ESUS110281. doi: http://dx.doi.org/10.2495/ESUS110281

[7] Gurses, A., Doymus, K. \& Bayrakceken, S., Evaluation of response of brown coal to selective oil agglomeration by zeta potential measurements of the agglomerates. Fuel, 76, pp. 1439-1444, 1997. doi: http://dx.doi.org/10.1016/S0016-2361(97)00121-X

[8] Krysyna, J. \& Barend, C.J., Relating coal oxidation and hydrophobicity: a petrographic approach. Fuel, 75, pp. 1611-1616, 1996. doi: http://dx.doi.org/10.1016/S0016-2361(96)00154-8

[9] Wang, Q., Niida, N.H., Apar, P., Chen, Q., Gui, L., Qian, Q., Mitsumura, N., Endou, T., Animesh, S. \& Kurokawa, H., Clarification of the reaction at the solution interface of pyrite during oil agglomeration for developing desulfurization and coal cleaning efficiency. WIT Transactions on Ecology and the Environment, Vol. 176, Energy and Sustainability IV, ed. C.A. Brebbia, WIT Press: Southampton, pp. 303-313, 2013, ISSN 1743-3541, doi: 10.2495/ESUS130261. doi: http://dx.doi.org/10.2495/ESUS130261

[10] Strydom, C.A., Bunt, J.R., Schobert, H.H. \& Raghoo, M., Changes to the organic functional groups of an inertinite rich medium rank bituminous coal during acid treatment processes. Fuel Processing Technology, 92, pp. 764-770, 2011. doi: http://dx.doi.org/10.1016/j. fuproc.2010.09.008

[11] Geng, W., Nakajima, T., Takanashi, H. \& Ohki, A., Analysis of carboxyl group in coal and coal aromaticity by Fourier transform infrared (FT-IR) spectrometry. Fuel, 88, pp. 139-144, 2009. doi: http://dx.doi.org/10.1016/j.fuel.2008.07.027

[12] Ozkan, A., Ucbetiay, H. \& Duzyol, S., Comparison of stages in oil agglomeration process of quartz with sodium oleate in the presence $\mathrm{Ca}$ and $\mathrm{Mg}$ ions. Journal of Colloid and Interface Science, 329, pp. 81-88, 2009. doi: http://dx.doi.org/10.1016/j.jcis.2008.09.073

[13] Das, D., Dash, U., Nayk, A. \& Misra, P.K., Surface engineering of low rank Indian coals by starch - based additives for the formulation of concentrated coal - water slurry. Energy Fuels, 24, pp. 1260-1268, 2010. doi: http://dx.doi.org/10.1021/ef900921c

[14] Niu, S., Han, K. \& Lu, C., Release of sulfur dioxide and nitric oxide and characteristic of coal combustion under the effect of calcium based organic compounds. Chemical Engineering Journal, 168, pp. 255-261, 2011. doi: http://dx.doi.org/10.1016/j.cej.2010.10.082 